\title{
PEMANFAATAN SAMPAH MENJADI DEKORASI BUNGA GUNA UNTUK MEMINIMALISIR SAMPAH DAN MENINGKATKAN PENDAPATAN EKONOMI SAMPINGAN PADA IBU-IBU PKK DI DUSUN PAELOAN DESA SUMBERBARU
}

\author{
Lilit Biati, Ridwan \& Arif Hariyanto \\ IAI Darussalam Blokagung Banyuwangi, Indonesia \\ IAI Darussalam Blokagung Banyuwangi, Indonesia \\ Universitas Ibrahimy Situbondo, Indonesia \\ lilitbiati@gmail.com \\ mbahjohn74@gmail.com \\ arifalrhandy@gmail.com
}

\begin{abstract}
: the use of plastics can provide convenience and practicality, plastic also has a particularly bad impact on the environment. Plastics contain artificial inorganic materials which are composed of chemicals that are dangerous enough for the environment. This waste of plastic is very difficult to decompose naturally. To decompose plastic waste itself, it takes approximately 80 years to completely degrade. Currently the government is increasingly active in providing awareness to the public to reduce the use of plastics in life, then providing teaching on how to treat plastic waste into goods that are beneficial to life.

Participatory action research has three word elements, all of which have a connection between Participation, Action and Research. In the process of carrying out social change for the better, it must involve all levels of society who are the object or target as well as the subject where the social change must be carried out. Utilization of organic waste which can be used as various kinds of valuable creativity and has a selling price that can improve the community's economy, and also make the environment clean and healthy. Making society in a harmonious and peaceful environment. There won't be any problems. The village will be safe and secure.
\end{abstract}


Keywords: Utilization of Waste, Increasing Economic Income

\section{Pendahuluan}

Desa Sumberbaru adalah sebuah nama desa di wilayah kecamatan singojuruh kabupaten banyuwangi, provinsi jawa timur. merupakan desa yang baru terbentuk beberapa tahun yang lalu dan merupaka pemekaran dari desa kemiri. mayoritas penduduknya adalah suku osing dan mayoritas penduduknya beragama islam. desa sumberbaru sebelah utara berbatasan dengan desa parangharjo kecamatan songgon, sebelah selatan desa gendoh kecamatan sempu, sebelah timur desa kemiri kecamatan singojuruh, sebelah barat desa sragi kecamatan songgon. desa sunberbaru memiliki potensi yang sangat besar disektor pertanian. mayoritas penduduknya bekerja sebagai petani dan buruh tani.

Secara topografi desa sumberbaru berupa dataran sedang yang mana wilayahnya bagian selatan dikelilingi oleh sungai kumbo, sebagian sungai kemapak dan bukit kelasi, sedang wilayah utara dikelilingi oleh sungai badeng, suhu udara desa sumberbaru berkisar 21 - 27 derajat celcius, dengan ketinggian rata-rata dari permukaan air laut kurang lebih $65 \mathrm{~m}$ dpl sedangkan curah hujan rata-rata tiap tahun berkisar 1000-2000 mm dengan demikian kondisi alam desa Sumberbaru cukup sejuk. 
Pada awal berdirinya desa sumberbaru berawal dari kesepakatan masyarakat yang ingin mengurus surat menyurat dengan cepat dan dekat, maka seluruh masyarakat bersepakat untuk mendirikan desa sendiri dan meminta kepada pemerintah desa induk yaitu desa kemiri untuk memecahkan desa dan mendirikan desa sendiri. Pada waktu itu pemerintah desa kemiri bersikukuh tidak mau, akan tetapi berkat perjuangan tokoh-tokoh masyarakat dan ridho allah sehingga sepakatlah desa. Setelah sepakat dipecah pada waktu masih desa persiapan dan belum definitive terjadi lagi perebutan tapal batas yaitu dukuh sidomulyo atau kampung anyar, sehingga sampai pemerintah kabupaten banyuwangi turun untuk melakukan jajak pendapat. Sehingga, hasil keputusan jajak pendapat dukuh tersebut sekarang tetap masuk desa kemiri. Setelah pada tahun 2000 bulan desember ditetapkanlah desa ini menjadi desa definitive dan dinamakanlah desa sumberbaru, dikarenakan didesa ini banyak terdapat sumber-sumber mata air dan sepakatlah tokoh masyarakat menamakan desa sumberbaru karena banyaknya sumber tersebut, dan kata baru diambil dari sesuatu yang memang baru berdiri. Sehingga menjadi nama sumberbaru. Desa sumberbaru terdiri dari tiga dusun yaitu umbulrejo, kendal dan paeloan.

Dusun paeloan desa sumberbaru mayoritas usahanya adalah 
sebagai petani. di desa sumberbaru terkenal dengan desa yang sangat subur dan sejuk. dengan dilihat dari nama desa tersebut desa sumberbaru banyak sekali sungai-sungai yang mengalir disepanjang jalan. akan sangat disayangkan sekali di desa yang sejuk dan indah tersebut apabila masyarakatnya masih belum bisa menjaga lingkungan dengan baik, yakni membuang sampah sembarangan.

Kurang sadarnya masyarakat dalam menjaga lingkungan disebabkan karna minimnya pendidikan. di desa tersebut masih minim sekali tentang pendidkan dan ilmu pengetahuan. hal ini mengacu pada masyarakatnya yang lebih mementingkan uang dan pekerjaan dari pada pendidikan. dilihat dari kegiatan sehari-hari mereka mulai bangun tidur sampai sore mereka bekerja untuk memenuhi kebutuhan hidupnya. banyak sekali anak-anak yang outus sekolah karena alasan bekerja dan itu merupakan kemauan dari orang tua anak-anak tersebut.selain itu di desa tersebut pendidkan agamanya juga sangat kurang sehingga masyarat tidak tau akan pentingnya peran agama dalam menjaga lingkungan.

Disamping itu di desa sumberbaru rata-rata setiap kepala keluarga belum mempunyai lahan untuk tempat pembuangan sampah. hal tersebut mengakibatkan masyarakat membuang sampah dengan sembarangan seperti di pinggir jalan, sungai bahkan ada yang 
membuang di depan rumah tetangga sehingga terjadi percekcokan.

Kondisi di atas menjadi peluang bagi peneliti untuk berpartisipasi dalam menanggulangi pembuangan sampah. pada saat inilah peneliti mulai merencanakan dan merintis bagaimana cara penanggulangan sampah yang baik.

Plastik merupakan material yang sangat akrab dalam kehidupan manusia. kemajuan teknologi plastik membuat aktivitas produksi plastic terus meningkat. hamper setiap produk menggunakan produk plastic sebagai kemasan atau bahan dasar. material plastik banyak digunakan karena memiliki kelebihan dalam sifatnya yang ringan, transparan, tahan air, serta harganya relatif murah dan terjangkau oleh semua kalangan masyarakat.

\section{Metode}

Pada dasarnya PAR (Participatory action research) memiliki tiga unsur kata yang kesemuannya itu memiliki keterkaitan antara Partisipasi, Aksi dan Riset. Ketiga kata tersebut saling berkaitan. Dengan demikian dapat diartikan bahwa setiap hasil riset harus diimplemantasikan ke dalam bentuk aksi. Dalam proses melakukan perubahan sosial ke arah yang lebih baik tersebut, haruslah melibatkan semua lapisan masyarakat yang menjadi objek atau sasaran sekaligus menjadi subjek di mana perubahan sosial itu harus dilakukan. Di sinilah 
letak partisipasi sebagai pemahaman bahwa dalam segala tindakan, seorang peneliti bersama masyarakat berupaya untuk merubah tatanan kehidupan sosial ke arah yang lebih baik.

Maka sebagai langkah awal sebelum melakukan peroses perubahan sosial tersebut, yang berada di Dusun Paeloan terlebih dahulu mengenali dan memahami secara mendalam tentang kondisi masyarakat beserta permasalahan yang meraka hadapi.

Keputusan suatu tindakan yang kita jadikan program, adalah pembuatan dekorasi bunga dari sampah guna untuk meminimalisir sampah. Menciptakan Desa yang bersih dari sampah memerlukan strategi pelaksanaan yang baik dan menarik hati ibu-ibu agar bisa berpartisipasi ikut serta dalam program ini, memerlukan contoh produk yang menarik, karena masyarakat Desa sangat kurang dalam hal kesadaran diri untuk memanfaatkan sampah. Oleh karena itu, kita memberikan sosialisasi tentang pemanfaatan sampah menjadi produk yang mempunyai nilai jual dan bermanfaat.

\section{Tenaga Kerja}

Tenaga Kerja yang dipakai dalam proses pembuatan dekorasi bunga ini adalah tenaga kerja yang berasal dari masyarakat sekitar yaitu masyarakat di Kecamatan Singojuruh Desa Sumberbaru.

2.Aspek Sumber Daya Manusia 
Sumber daya manusia yang terlibat dalam program ini sangat sederhana karena tidak membutuhkan biaya banyak, yakni hanya memanfaatkan barang bekas berupa sampah plastic. Mulai dari pengambilan sampah, pembersihan sampah, penjemuran sampah, serta pembuatan dekorasi bunga sampai menjadi barang siap untuk dipamerkan dan menjadi bunga hias.

\section{Hasil dan Diskusi}

Berdasarkan asumsi kementerian lingkungan hidup (klh), setiap hari penduduk indonesia menghasilkan $0,8 \mathrm{~kg}$ sampah per orang atau secara total sebanyak 189 ribu ton sampah/hari. Jumlah tersebut 15\% berupa sampah plastik atau sejumlah 28,4 ribu ton sampah plastik/hari (Pahlevi, 2012). Hal tersebut di tegaskan oleh Antonopoulos (2012) The input/output modeling of each waste management technology is quite complex due to various undefined processes. Artinya masukan dan keluaran model manajemen teknologi pengolahan sampah yang tidak diketahui prosesnya. Di satu sisi penemuan plastik ini mempunyai dampak positif yang luar biasa, karena plastik memiliki keunggulankeunggulan dibanding material lain. Tetapi di sisi lain, sampah plastik juga mempunyai dampak negatif yang cukup besar. Keunggulan plastik dibanding material lain diantaranya kuat, ringan, fleksibel, tahan karat, tidak mudah pecah, mudah diberi warna, mudah dibentuk, serta 
isolator panas dan listrik yang baik,sedangkan plastik yang sudah menjadi sampah akan berdampak negatif terhadap lingkungan maupun kesehatan manusia. Menurut pandangan Siddiqui (2013) contribution of plastics to human health is difficult to ignore. Plastic based packaging with the above-mentioned properties ensures reaching the best, hygienic and unadulterated product to the masses. Melalui terjemahan bebas kontribusi plastik untuk kesehatan manusia sulit untuk diabaikan, kemasan berbasis plastik dengan sifat-sifat yang disebutkan di atasmemastikan mencapai yang terbaik, produk higienis dan murni untuk masyarakat.

Dari penelitian yang dilakukan oleh Jurusan Teknik Mesin Universitas Gadjah Mada (UGM) Yogyakarta bekerjasama dengan Tokyo Institute of Technology, Jepang yang dipimpin oleh Guru Besar Fakultas Teknik UGM Prof. Dr.Ing Harwin Saptoadi. Semua 4 jenis plastik bisa didaur ulang menjadi bahan bakar alternatif, karena pada dasarnya plastik sendiri berasal dari minyak bumi, sehingga kita hanya tinggal mengembalikannya ke bentuk semula (Bambino, 2014). Penelitian lain dilakukan oleh Aprian Ramadhan P. dan Munawar Ali(2011) menunjukkan bahwa konversi volatile matter yang dapat dicapai 80,2\%, dan itu terjadi pada waktu 60 menit dan suhu 420oC.

Penelitian yang dilakukan oleh Nurhenu Karuniastuti dengan 
judul 'Bahaya Plastik Terhadap Kesehatan Dan Lingkungan' mengemukakan bahwa Plastik adalah salah satu bahan yang dapat kita temui di hampir setiap barang. Menurut penelitian, penggunaan plastik yang tidak sesuai persyaratan akan menimbulkan berbagai gangguan kesehatan, karena dapat mengakibatkan pemicu kanker dan kerusakan jaringan pada tubuh manusia (karsinogenik). Selain itu plastik pada umumnya sulit untuk didegradasikan (diuraikan) oleh mikro organisme. Sampah plastik dapat bertahan hingga bertahun-tahun sehingga menyebabkan pencemaran terhadap lingkungan. Sampah plastik tidaklah bijak jika dibakar karena akan menghasilkan gas yang akan mencemari udara dan membahayakan pernafasan manusia, dan jika sampah plastik ditimbun dalam tanah maka akan mencemari tanah, air tanah. Untuk itu perlu diketahui tentang jenis-jenis utama plastik : kode PET, HDPE, PVC, LDPE, PP, PS, OTHER sehingga jika memakai plastik yang lebih aman yaitu dengan kode HDPE, LDPE, PP, OTHER ( kecuali PVC ) dan penanggulangan terhadap sampah plastik

Menjaga lingkungan yang sehat merupakan upaya untuk mencegah penyakit atau gangguan kesehatan dari faktor risiko lingkungan untuk mewujudkan kualitas lingkungan yang sehat baik dari aspek fisik, kimia, biologi, maupun sosial. Kualitas kesehatan berawal dari kesehatan lingkungannya yang ditentukan melalui 
pencapaian atau pemenuhan standar baku mutu kesehatan lingkungan dan persyaratan kesehatan.

Dalam kehidupan sehari-hari, manusia tidak bisa lepas dari kegiatan penggunaan barang untuk mendukung dan memenuhi kebutuhan hidup. Penggunaan barang yang beragam tersebut baik berupa penggunaan untuk keperluan primer, sekunder maupun tersier. Salah satu barang yang paling sering digunakan oleh manusia untuk pemenuhan keperluan hidupnya adalah berupa plastik. Plastik merupakan bahan umum yang seringkali digunakan sebagai bahan kemasan, baik untuk makanan, minuman, atau barang yang dikemas lainnya.

Penggunaan plastik pada dasarnya dapat memberikan kemudahan dan kepraktisan tersebut, plastic juga memberikan dampak buruk khususnya bagi lingkungan. Plastic mengandung bahan anorganik buatan yang tersusun dari bahan-bahan kimia yang cukup berbahanya bagi lungkungan. Limbah daripada plastic ini sangatlah sulit untuk diuraikan secara alami. Untuk menguraikan sampah plastik itu sendiri membutuhkan kurang lebih 80 tahun agar dapat terdegradasi secara sempurna. Oleh karena itu penggunaan bahan plastic dapat dikatakan tidak bersahabat ataupun konservatif bagi lingkungan apabila digunakan tanpa menggunakan batasan tertentu. 
Menyadari dampak buruk akibat pemakaian plastic terhadap lingkungan, saar ini pemerintah semakin giat memberikan kesadaran terhadap masyarakat untuk mengurangi penggunaan plastic dalam kehidupan, kemudian memberikan pengajaran mengenai cra pengolahan limbah plastic menjai barang yang bermanfaat bagi kehidupan.

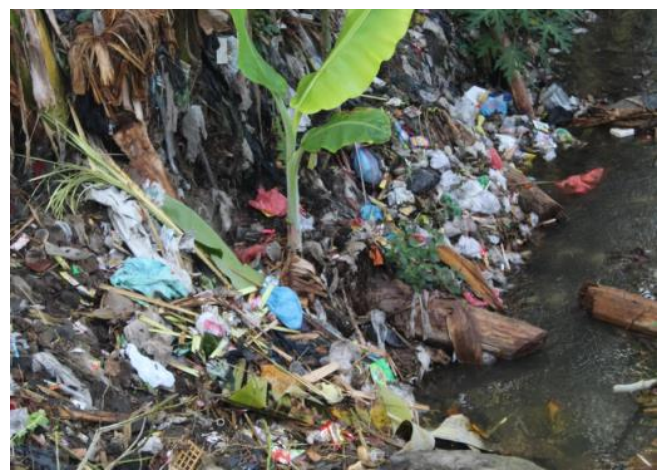

gambar 01. Banyaknya sampah dipinggir sungai 


\section{Pohon Masalah}

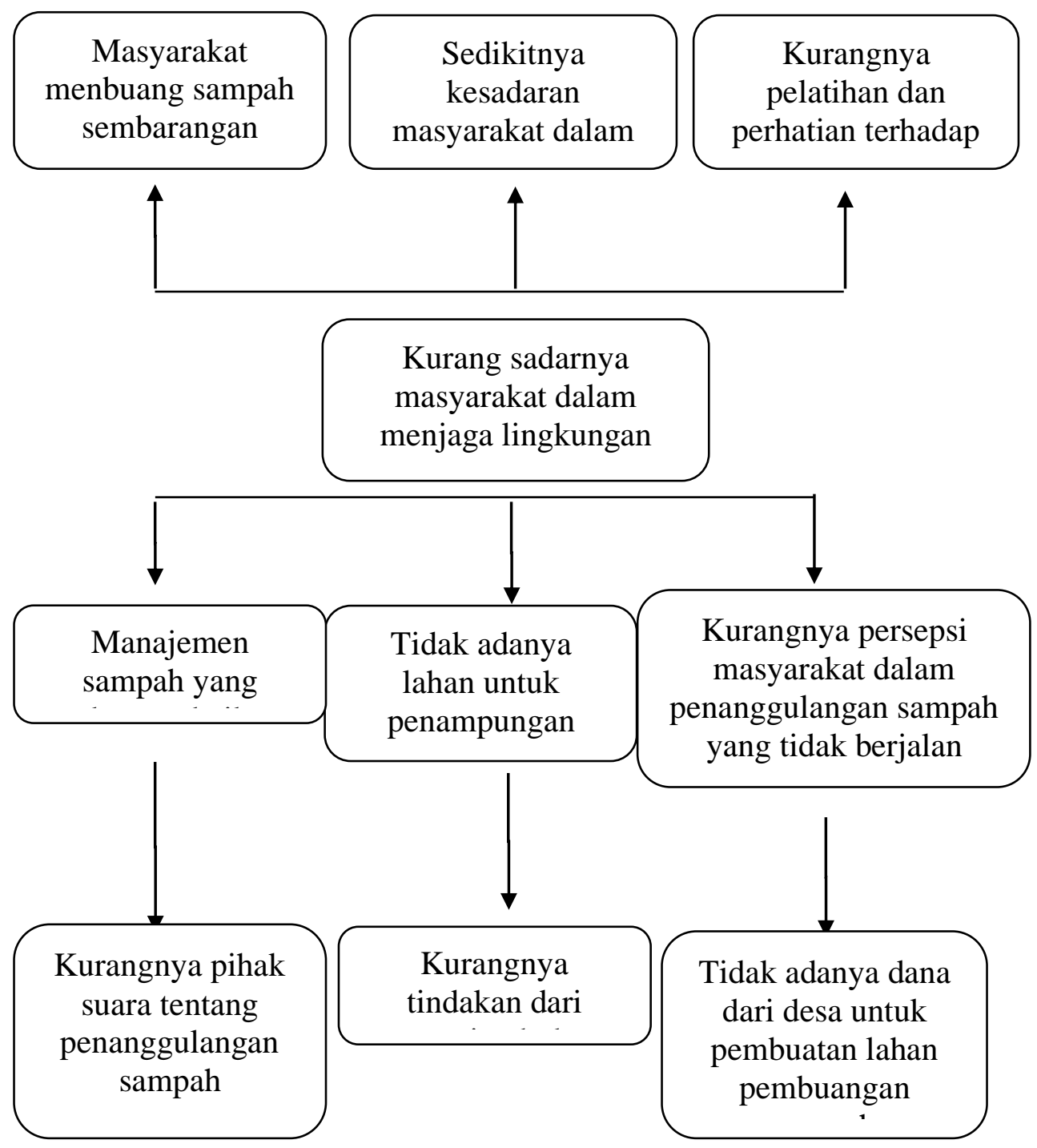

Gambar: Dusun Paeloan Pohon Masalah 
Kegiatan yang dilakukan dengan mendekorasi bunga adalah bunga yang dirangkai secantik mungkin yang dibuat dari barang bekas, yaitu sampah plastik atau kresek dirangkai menjadi bunga-bunga hias yang cantik guna untuk meminimalisir sampah yang sangat mengganggu jalan aliran sungai, juga untuk menciptakan ruang tamu yang indah, nyaman, dan memiliki nuansa romantis buat para tamu yang hadir untuk mertamu di setiap rumah tertentu.

jenis dekorasi bunga ini memiliki bentuk yang hampir mirip dengan bentuk bunga dahlia. dekorasi bunga yang telah kita buat guna untuk persiapan sample atau contoh untuk sosialisasi pelatihan sampah menjadi dekorasi bunga pada ibu-ibu pkk, banyak digemari oleh semua orang disekitar desa sumberbaru khususnya tetangga posko kami yang sangat suka memuji hasil dekorasi yang telah kita buat untuk sample, dan sangat didukung penuh oleh masyarakat desa sumberbaru.

\section{Persiapan material bahan baku}

Peralatan kerja

\begin{tabular}{|l|l|l|}
\hline No & Nama barang & Jumlah \\
\hline 1 & Gunting & 4 \\
\hline 2 & Kawat & \\
\hline 3 & Lem tembak & 10 \\
\hline 4 & Kardus & 2 \\
\hline
\end{tabular}




\begin{tabular}{|l|l|l|}
\hline 5 & Korek api & 4 \\
\hline 6 & Tali raffia & 2 \\
\hline
\end{tabular}

Tabel 1. Peralatan kerja

Perlengkapan kerja

\begin{tabular}{|l|l|l|l|}
\hline No & Jenis & Jumlah & Harga \\
\hline 1 & Tenaga atau jasa & & - \\
\hline 2 & Kresek & 1 pcs & Rp. 7000,- \\
\hline 3 & Transport & 1 liter bensin & Rp. 10000,- \\
\hline
\end{tabular}

tabel 2. Perlengkapan kerja

Langkah-langkah untuk membuat dekorasi bunga dari bahan sampah organik:

1. Cuci kresek atau palstik yang diambil dari limbah sampah tersebut hingga bersih sehingga layak digunakan untuk kerajinan, kemudian dijemur hingga kering,

2. Kemudian potong memanjang kresek atau plastic yang telah kering dengan gunting, lalu buat lupatan-lipatan plastic tersebut hingga mengecil dan gunting kedua ujungnya dengan bentuk runcing seperti ujung mahkota bunga dahlia. 
3. Setelah plastic berbentuk runcing potonglah menjadi dua bagian atau sesuai selera bunga yang akan dibuat. Misalnya ukuran kecil, sedang, atau besar.

4. Lipat plastic yang telah dipotong dengan kedua tangan sesuai selera hingga ujung plastic habis, kemudian ikat ikat dengan dengan tali raffia hingga erat.

5. Rapikan menjadi bentuk bunga dahlia atau kibarkan plastic hingga berbentuk bunga.

6. Ambil kawat kemudian lilitkan dibagian tengah mahkota bunga yang telah berbentuk bunga dahlia tadi, lalu lilitkan kawat hingga mengikuti bentuk batang kawat tersebut.

7. Hias atau lapisi batang kawat tersebut dengan plastic atau kresek yang dipotong kecil memanjang. Warna menyesuaikan selera yang membuat. Dengan cara lilitkan plastic pada kawat hingga ujung kawat, kemudian kunci dengan solasi atau sejenisnya yang bisa untuk mengunci.

8. Bentuk putik mahkota bunga dengan bungkus snack (warna sesuai selera) menjadi bulatan kecil hingga sedikit mirip dengan putik bunga dahlia. 
9. Lalu tempelkan putik tersebut dibagian tengah bunga dan tempelkan dengan lem tembak yang telah dipanaskan dengan korek api.

10.Buatlah bunga mirip seperti langkah awal hingga banyak (sesuai selera)

11.Kemudian jika hasil bunga sudah banyak, rangkai bunga menjadi dekorasi bunga cantik (sesuai selera)

12.Ikat rangkaian bunga yang telah dirangkai tadi dengan kawat atau tali raffia.

13.Kaitkan batu dengan kawat pada bagian bawah bunga tersebut hingga bunga kuat untuk berdiri tegak.

14.Lapisi atau bungkus bagian bawah yang dikaitkan batu tersebut dengan plastic sisa, kemudian diikat dengan tali raffia.

15. Masukkan kedalam vas bunga dan bisa menggunakan vas dari kardus atau membeli jadi.

16.Hias pot bunga dengan bungkus snack (sesuai selera)

17.Dekorasi bunga dari sampah plastic siap dibuat hiasan meja ruang tamu atau selainnya serta dikemas dan dipasarkan. 


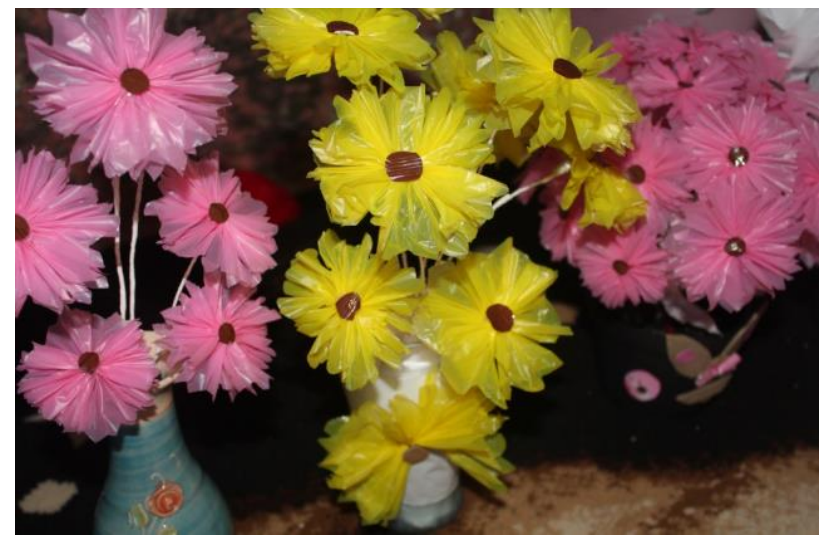

Data yang diperoleh menggambarkan bahwa sampah organic yang berada di dusun paeloan desa sumberbaru ini termasuk masalah yang sangat sulit diselesaikan selama 17 tahun ini. dan masyarakat setempat sangat sulit di kendalikan agar tidak membuang sampah pada sembarang tempat seperti sungai, jalan, dan selokan. sampah-sampah ini banyak dijumpai disekitar daerah tersebut, dan menjadi kendala pengurus desa bagai mana cara menyelesaikan masalah tersebut, karena masalah ini tidak juga di tangani oleh pemerintah. proses kegiatan ini dilakukan secara bersama-sama dan bergantian tugas. dan kami langsung meninjau tempat yang menjadi masalah sampah. sampah organic merupakan jenis sampah yang sulit sekali di daur ulang kembali. sampah juga mengakibatkan dampak buruk bagi gangguan kesehatan dan pernafasan. jadi kami mengambil solusi bagaimana 
caranya agar sampah-sampah tidak mengganggu aliran sungai dan jalan-jalan. kami mengambil langkah dengan membuat vas bunga dari sampah plastic dan snak-snak yang sudah tidak terpakai dan manfaat dari itu semua adalah untuk memanfaatkan dan meminimalisir sampah yang terbuang sia-sia.

Pada minggu pertama dan kedua kami melakukan penelitian di berbagai dusun di sumberbaru seperti dusun paeloan, kendal, dan umbulsari. dari berbagai dusun tersebut terdapat macam-macam masalah yang terjadi salah satunya yaitu terjadinya percemaran sampah pada aliran-aliran sungai yang sangat mengganggu pencemaran air sungai, maka dapat dipecahkan masalah yaitu menanggulangi sampah yang berserakan dimana-mana. dari masalah tersebut kami memecahkan masalah ingin membuat lingkungan menjadi bersih yaitu dengan mengolah limbah organic menjadi bahan kerajinan seperti vas bunga yang terbuat dari bahan-bahan sampah. setelah melakukan survey di berbagai dusun dan berbagai masalah telah dijelaskan dari berbagai dusun tersebut dan kami menemukan dari masalah-masalah tersebut yaitu masalah sampah yang menjadi masalah warga yang kebanyakan kurang sadarnya warga dalam membuang sampah pada aliran-aliran sungai. kami melakukan observasi di ibu kades dan kami mendapatkan dukungan penuh untuk membuat dekorasi bunga dari 
sampah-sampah yang berserakan tersebut. karena memang program yang kita ambil menjadi par itu dulunya sudah menjadi rencana kedepan pak kades dan ibu kades, tetapi tidak terlaksana hingga saat ini, karena kurang partisipasinya warga desa sumberbaru dan kurang sadarnya pemikiran keterbelakangan mereka yang terus bersikukuh acuh terhadap lingkungan. dan akhirnya di situ kami melakukan perkenalan PAR (Participatory action research) kami dan meminta dukungan agar kegiatan berjalan dengan lancer. berawal dari melakukan sosialisasi pengarahan terlebih dahulu kepada warga desa sumberbaru guna untuk mengubah pola pikir mereka agar ikut mensukseskan desa yang bebas sampah. dan saat itu ternyata ibu-ibu sangat senang sekali dengan program kami dan sangat mendukung kami atas program tersebut.

eksperimen pembuatan vas bunga dari sampah bekas yang didaur ulang menjadi bahan kerajinan dengan berbagai macam alat-alat yang digunakan untuk membuat vas bunga diantaranya gunting, lem tembak, solasi, korek api, kawat, tali rafia, kresek bekas, batu kecil, dan kardus bekas. serta mengajari rekan-rekan bagaimana cara membuat vas bunga tersebut. dan akhirnya kami bersepakat dengan program tersebut karena sangat bermanfaat bagi masyarakat dan lingkungan. kami melakukan eksperimen pembuatan sampah dari bahan bekas, hari ke 3 ( 
tanggal 13 agustus 2019 ) dan melakukan sosialisasi terlebih dahulu sebelum melakukan kegiatan par kepada ibu-ibu pkk. dan mereka sepakat untuk melakukan eksperimen percobaan pembuatan vas bunga dari sampah tersebut.

Pelaksanaan meliputi penyusunan materi sosialisasi dan mempersiapkan bahan-bahan yang akan di demonstrasikan kepada ibu pkk. waktu pelaksanaan program ditempuh dalam waktu 3 hari minggu ke tiga : hari ke 1 dan ke 2 ( tanggal 13-14 agustus 2019) kami melakukan eksperimen pembuatan bersama ibu pkk ( tanggal 15 agustus 2019 ) sosialisasi kepada ibu pkk. jadi kami melakukan program par pada tanggal 15 agustus 2019 pukul 14.00 di rumah ibu ela yang sebagai ketua pengajian fatayat di dusun paeloan. dan akhirnya par kami mengambil kegiatan program kelompok yang berjudul pemanfaatan sampah menjadi dekorasi bunga guna untuk meminimalisir sampah dan meningkatkan pendapatan ekonomi sampingan pada ibu ibu pkk didusun paeloan desa sumberbaru.

Ibu pkk terdapat 40 orang yang mengikuti pengajian rutinan pada hari senin pukul 14.00. kami melatih kesemua ibu pkk untuk berlatih cara membuat vas bunga. dan kami mengajari satu persatu hingga mereka benar-benar faham dan jelas. setelah itu kami melepas ibu pkk untuk membuat sendiri dengan selera tersendiri. mereka sangat antusias 
dan bersemangat. tidak butuh waktu lama untuk melatih ibu pkk.

Setelah sosialisasi selesai kami membagikan hasil kerajinan kami kepada ibu pkk agar dapat melihat hasil kerajinan yang kami buat sekaligus menjadi contoh buat ibu-ibu pkk yang hendak melakukanpercobaan untuk membuat kerajinan dekorasi bunga yang telah kita sosialisasikan.

Dari program yang kami angkat, kami memaparkan program tersebut melalui sosialisasi tentang tata cara pengolahan sampah menjadi sampah yang siap digunakan untuk kerajinan bunga serta memberikan pengetahuan tentang cara memasarkan produk tersebut agar dikenal masyarakat dan mendemonstrasikan hasil kerajinan yang telah kami buat sebelumnya. mulai dari pengambilan sampah yang diambil dari sampah yang berserakan dimana-mana seperti sungai dan jalan-jalan. yang berawal dari sampah basah kita jadikan sampah kering dengan cara dicuci terlebih dahulu kemudian dijemur . kami menyampaikan apa saja bahan-bahan yang diperlukan untuk membuat kerajinan dekorasi bunga yang kita buat dari sampah tersebut. berikut adalah bahan-bahan yang digunakan untuk membuat dekorasi bunga dari sampah yang kita manfaatkan, guna untuk meminimalisir sampah yang tertimbun. bahan-bahan : plastic atau kresek bekas, kawat kecil sisa dari bahan pembangunan, tali raffia, lem tembak, solasi, bungkus 
snack yang sudah terbuang/ bekas, kardus sisa, dan batu-batuan (krikil). dan alat-alat : gunting, korek api, dan silet.

Sudahkah anda mencoba membuat kerajinan dekorasi bunga dari bahan sampah dekorasi bunga ini sangat menguntungkan kita sekali, selain menghasilkan uang untuk dijual kita juga bisa hidup sehat tanpa polusi, karena menjaga lingkungan itu sangat penting sekali bagi jasmani dan rohani. anda tertarik untuk membuat dekorasi bunga, mungkin anda ingin mengetahui cara pembuatan bagi anda yang tertarik dengan dekorasi bunga dari sampah ini, maka anda bisa menyimak ulasan lengkap berikut:

1. peluang bisnis untuk pembuatan dekorasi bunga dari bahan sampah tersebut

2. memulai merancang pembuatan

3. pelaku tujuan dari pembuatan tersebut

4. konsumen

5. bahan-bahan yang mudah didapatkan

6. peralatan yang digunakan

7. harga

8. strategi

9. memanfaatkan sekitar

10.lingkungan menjadi bersih 


\section{1.lancarnya aliran sungai}

12.tidak tercemarnya air sungai

13.tidak ada limbah yang berserakan

14.mempercantik dekorasi meja

\section{Kesimpulan}

Dalam pemanfaatan barang bekas menjadi dekorasi bunga harus melibatkan banyak pihak dalam meminimalisir sampah. Bukan hanya masyarakat namun juga harus mendapat dukungan dari pemerintah desa atas penanganan sampah yang belum terselesaikan selama 17 tahun ini. Fasilitas dalam pengelolaan tempat pembuangan sampah sangat dibutuhkan terutama dana keuangan. Jika pemerintah desa bisa menyediakan maka akan mudah untuk mengajak masyarakat dalam membuang samapah pada tempat yang sudah disediakan. Dan dalam upaya untuk mengajak masyarakat agar berminat dalam pengelolaan sampah disisi kami memberikan saran kepada masyarakat terutama kepada ibu-ibu PKK untuk memanfaatkan sampah organic menjadi dekorasi bunga guna untuk meminimalisir sampah. Selain memberikan saran kami juga memberikan saran tentang cara membuat dekorasi vas bunga yang akan dibuat.

Dari pembahasan di atas kesimpulan yang dapat diambil adalah pemanfaatan sampah organic yang bisa di jadikan berbagai macam 
kreatifitas yang bernilai dan memiliki harga jual yang dapat meningkatkan perokonomian masyarakat, dan juga membuat lingkungan menjadi bersih dan sehadzssdft. Menjadikan masyarakat dalam lingkup yang harmonis dan tentram. Tidak akan ada masalahmasalah yang terjadi. Desa akan menjadi aman dan tentram.

\section{Daftar Pustaka}

Bahari, Adnan, dkk., Sampah Plastik Sebagai Alternative Untuk Campuran Pembuatan Batu Alam Dan Aplikasinya. Riau, 2010

Dani Sucipto Cecep, Teknologi Pengolahan Daur Ulang Sampah, Gosyen Publishing, Yogyakarta, 2012

Dantje, dkk, Pengaruh Penambahan Cacahan Limbah Plastik Jenis High Density Polyethylene (HDPE) Pada Kuat Lentur Beton. Teknik Sipil, Universitas Nusa Cendana, 2012

Dian, Pengaruh Pemanfaatan Limbah Plastik HDPE Terhadap Beton". Teknik Sipil. Univesitas MUhammadiyah Surakarta, 2008

Dipohusodo Istimawan, Struktur Beton Bertulang, Gramedia: Jakarta, 1994

Elia,Richardo, dkk. Studi Eksperimental Kuat Tekan Dan Serapan Air Bata Ringan Celluler Lightweight Concrete Dengan Tanah Putih Sebagai Agregat. Teknik Sipil, FST Udana, 2014 
Mulyono, T. Teknologi Beton, Andi, Yogyakarta, 2004.

Nurhenu Karuniastuti, Bahaya Plastik Terhadap Kesehatan Dan Lingkungan' Jurnal Forum Teknologi vol.03 No.1

Ristina Dkk. Pengaruh Penggunaan Bottom Ash Sebagai Pengganti Semen Terhadap Campuran Batako Terhadap Kuat Tekan Batako, Jurnal Rekayasa Sipil, 2012

Staf Desa Sumberbaru, Buku Profil Desa Sumberbaru, Banyuwangi, 2018 


\section{JURNAL}

\section{As-Sidanah}

Vol. 02 No. 2, Oktober 2020 